\title{
Molecular Modeling of Complexation Behavior of p-tert-Butylcalix[5]arene Derivative toward Butylammonium Ions
}

\author{
Jong-In Choe and Suk-Kỵu Chang \\ Department of Chemistry, Chung-1ng University, Seoul 156-756, Korea \\ Received September 11, 2001
}

\begin{abstract}
Using several molecular modeling programs we have performed computer simulations to investigate the complexation behaviors of an ester derivative of p-tert-butylcalix[5]arene (1e) toward a variety of butylammonium ions. Semi-empirical AMl method was used for calculating the binding energies and the formation enthalpies. MM and CVFF forcefields for molecular mechanics calculations were adapted to express the complexation energies of the host. Molecular dy namics were performed to the calculated complex sy'stems to simulate the ionophoric behavior of the host-giest complexes. The absolute Gibbs free energies of the host (1e) complexed with four kinds of butylammonium ions have been calculated using the Finite Difference Thermody'namic Integration (FDTI) method in Discover. Calculation results show that the trend in complex formation is $n-\mathrm{BuNH}_{3}{ }^{-}>$iso- $\mathrm{BuNH}_{3}{ }^{-}>\sec -\mathrm{BuNH}_{3}{ }^{+}>$tert $-\mathrm{BuNH}_{3}{ }^{+}$. which is in good agreement with the experimental results.
\end{abstract}

Keywords : Calix[5]arene, Butylanmonium ions, Molecular modeling. Molecular recognition.

\section{Introduction}

Selective recognition of biologically inportant organic ammonium guests attracts much research interests. which results in developments of many sophisticated host systems. ${ }^{1-5}$ Among the many of the supramolecular systems. calixarene derivatives having suitable binding sites seem to be relatively useful for the recognition of organic ammoniun ions. "The cation- $\pi$-electron interactions are known to play an important role in the molecular recognition of ammonium ions as well as many positively charged guests by the electron-rich $\pi$-system of natural ${ }^{7}$ and synthetic ${ }^{8}$ hosts. Selective endo-calix complexations of alkylanmonium cations by functionalized (1.3)-p-tert-butylcalix[5]crown ether and by calix[5]arene-based molecular vessels (1b-e) have been evidenced by ${ }^{1} \mathrm{H}$ NMR spectroscopy. ${ }^{10}$ In this case. for a given butylammonium guest ion. the stability of the complexes generally decreases in the following order: $1 \mathrm{e}$ $>1 \mathrm{~b}>1 \mathrm{c}>1 \mathrm{~d}$. Also. ester derivative of $p$-tert-butylcalix[5]arene (1e) appears to bind the linear $n-\mathrm{BuNH}_{3}^{+}$ion more selectively than other isomeric butylammonium cations. ${ }^{13}$

Complex formation of compounds containing benzene rings with ammonium cations was theoretically studied using many computational tecluniques including $a b$ initio calculations. ${ }^{\text {Il-is }}$ The reports show that two types of NH-aromatic $\pi$ and $\mathrm{CH}$ aromatic $\pi$ interactions. which are important in biological systems. are responsible for the binding. More recently. Kim et $a$. published charged hydrogen bonds versus cation- $\pi$ interaction for the origin of the high affinity and selectivity of novel receptors for $\mathrm{NH}_{+}^{-}$over $\mathrm{K}^{-}$ions. ${ }^{1+}$

Recently: Choe et al. reported the computer simulations on molecular recognition of alkylamines by ester derivatives of p-tert-buty'lcalix[6]arene. ${ }^{15}$ Endo-cone-shaped complex was reported as the most stable conformer among the different orientations of alkylammonium cations complexed inside the cone-shape host. Choe et al. ${ }^{16.17}$ also studied the molecular modeling of complexation of alky lammonium ions by p-tert-butylcalix[4]crown-6-ether. In those reports. the primary binding site of host for the recognition of alkylammonium guests was confirmed to be the central part of the crown moiety. The complexation energy calculations by MM. AM1. and $a b$ initio methods revealed that the alkylammonium cations having smaller and linear alkyl groups showed the better complexation efficiencies. ${ }^{16.17}$

In this paper. we report the simulation of the conformational and the molecular recognition behavior of tertbutyll ester derivative (1e) of p-tert-butylcalix[5]arene toward four different butylammonium guests. The main purposes are to understand more deeply the complexational behavior of the present host-guest system that would be helpful for the development of more elaborate host systems for butyl ammonium isomers as well as many related biologically interesting guests.

\section{Computational Methods}

The initial structures of host and guest molecules were constructed by HyperChem. ${ }^{19}$ In order to find optimized conformations. we executed conformational search by simulated annealing method. which is described in previous publication. ${ }^{16}$ We have adapted $\mathrm{MM}^{-}$forcefields to express the Molecular Mechanics (MM) $)^{\text {(t) }}$ energies of p-tert-butylcalix[5]aryl host. butylammonium cations. and complexes obtained thereof.

Semi-empirical Quantum Mechanical (AM1) Method. The conformations of the host and complexes obtained from MM/MD calculations of HyperChem and InsightII/Discover ${ }^{21}$ were fully re-optimized to estimate the binding energy and the enthalpy of formation of the compounds using AMl semi-empirical quantum mechanics. The default semi-empirical 
options (Restricted Hartree-Fock (RHF) spin pairing) were used except the followings: total charge $=0$, spin multiplicity $=1$ for neutral host $(\mathbf{1 e})$; total charge $=1$. spin multiplicity $=1$ for cationic guests and complexes.

Molecular Dynamics and Molecular Mechanics Calculations by InsightI/Discover ${ }^{\text {21 }}$ The lowest energy conformers of host and conmplexes obtained from the previous HyperChen MD, MM, and AMI runs were read by InsightII/ Discover. We have adapted Consistent Valence Forcefield (CVFF) to express the MM energies of $p$-tert-butylcalix[5]arene derivative, butylammonium cations, and complexes. The initial structure was subjected to a conformational search in which $300 \mathrm{~K}$ constant temperature MD was carried out for $3 \mathrm{~ns}$. Every $50 \mathrm{ps}$ structure taken during the $3 \mathrm{~ns}$ sllapshot was saved and the energies of these conformers were minimized to $0.01 \mathrm{kcal} / \mathrm{mol}$ gradient.

Absolute Gibbs Free Energy ${ }^{2 \hat{2}}$ by InsightII/Discover. The tecluique of absolute free energy is general and can be applied in transparent manner to systens in a vacuum or in solution. under any conditions of volume and/or temperature. See the references 15 and 22(f) for detailed explanation.

\section{Results and Discussion}

Conformational Characteristics of Calix[5]arene. Four different conformations (cone. a partial cone, two-[(1,2), $(1,3)]$-altennates) are possible for $p$-tert-butylcalix[5]arene. Although the shape of the calix[5]arene cavity cant. in principle, be tuned by changing the nature and bulkiness of substituents on both the upper and lower rims. ${ }^{18}$ the adaptation of cone conformation is essential for the selective inclusion of $\mathrm{RNH}_{3}{ }^{-}$ions. Therefore. we focused only to the cone conformers of the host for the complexation with the guest ions. Figure I shows the chemical structure of cone-type $p$ -
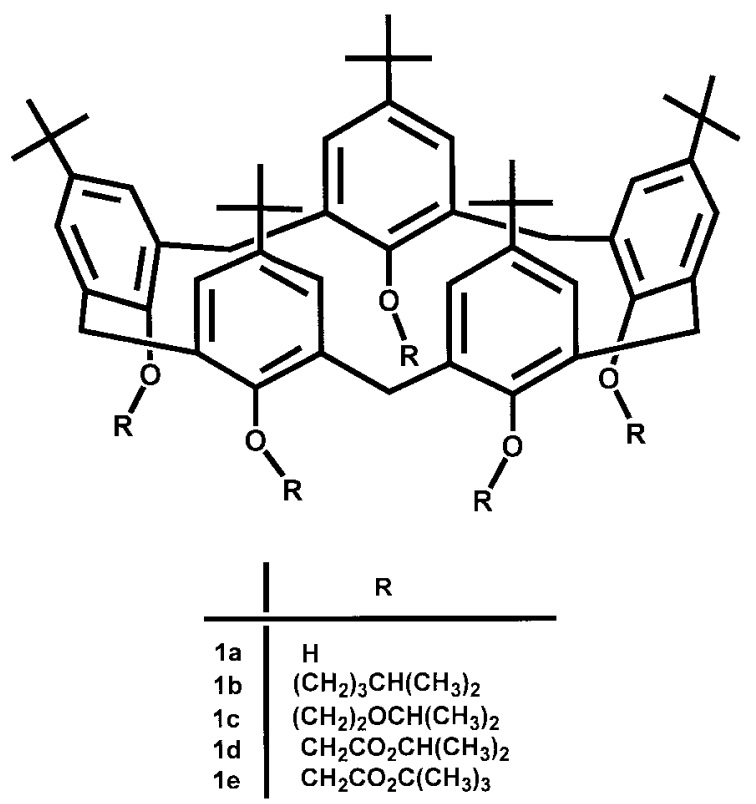

Figure 1. Chemical structure of $p$-tent-butylcalis[5]arene derivatives (1)

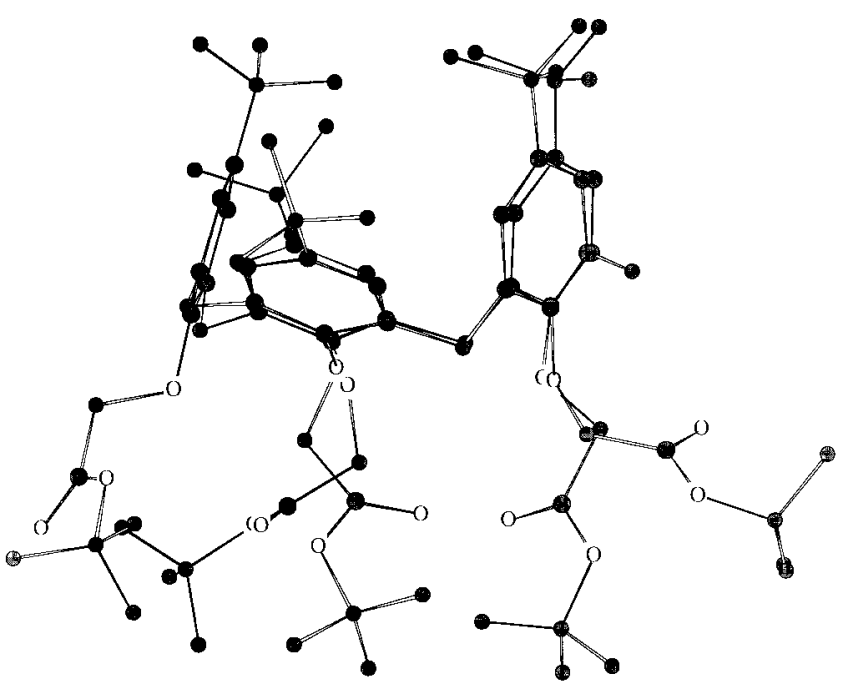

Figure 2. Calculated cone confonmation of free host (1e).

tert-butylcalix[5]ary] derivatives. Figure 2 displays the calculated cone conformation of free host (1e). Hydrogen atoms are omitted for clarity in Figures 1 and 2.

Endo-cone-type Complex. Four kinds of complex formation are possible for the different orientations (upper or lower rim of the host and up or down direction of alkylammonium ions for each location) of guest inside the cavity of calix[n] arene host. ${ }^{15}$ The NMR study on the complexation of $n$-butylammonium ( $n$-Bu) cation by alkyl p-tert-butylcalix[5] aryl derivative indicated that the guest is held tightly deep in the cone-shape aromatic cavity of calix[5]arene. thus forming endo-type complex. ${ }^{\text {li }}$ In there endo-complexation is unambiguously supported by the dramatic upfield shifts

Table 1. Binding Energies (kcal/mol $)^{a}$ of Host, But lammonium Ions, and Complexes

\begin{tabular}{|c|c|c|c|c|}
\hline \multirow{3}{*}{$\begin{array}{l}\text { Binding Energies } \\
\text { (AMl) }\end{array}$} & \multicolumn{4}{|c|}{ Butylammonium guest ${ }^{b}$} \\
\hline & $n-\mathrm{Bu}$ & $i s o-\mathrm{Bu}$ & $\mathrm{sec}-\mathrm{Bu}$ & $\operatorname{tent-Bu}$ \\
\hline & -1298.26 & -1296.78 & -1297.45 & -1296.39 \\
\hline Host & \multicolumn{4}{|c|}{ Complexes of host with guest } \\
\hline-22289.62 & -23645.80 & -23643.20 & -23631.11 & -2.3627 .42 \\
\hline le Complexation & -57.92 & -56.80 & -44.03 & -41.41 \\
\hline
\end{tabular}

${ }^{a}$ Error limits in these semi-empirical quantum mechanics calculations are 0.01 kcal : mol. ${ }^{~} \mathrm{Bu}=\mathrm{Butty}$ lammonium ion. "Complexation energy $=\mathrm{E}_{\text {Comples }}$ $-\mathrm{E}_{\mathrm{H} \leftrightarrow \mathrm{l}}-\mathrm{E}_{\mathrm{Gnex}}$

Table 2. Enthalpies $(\mathrm{kcal} / \mathrm{mol})^{\prime \prime}$ of Host, Butylammonium Ions, and Complexes

\begin{tabular}{|c|c|c|c|c|}
\hline \multirow{3}{*}{$\begin{array}{c}\Delta \mathrm{H}_{\mathrm{cal}} \\
(\mathrm{AMI})\end{array}$} & \multicolumn{4}{|c|}{ Butylammonium guest } \\
\hline & $n$-Bu & $i s o-\mathrm{Bul}$ & $s e c-B u l$ & tert-Bu \\
\hline & 123.526 & 125.008 & 124.329 & 125.397 \\
\hline Host & \multicolumn{4}{|c|}{ Complexes of host with guest } \\
\hline-618.35 & -552.74 & -550.14 & -538.05 & -534.36 \\
\hline 1e Complexation ${ }^{b}$ & -57.92 & -56.80 & -44.03 & -41.41 \\
\hline
\end{tabular}

"Error limits in these semi-empirical quantum mechanics calculations are 0.01 kcal mol. ${ }^{b}$ Complexation enthalpy $=\Delta \mathrm{H}_{\text {Complex }}-\Delta \mathrm{H}_{\text {Hasl }}-\Delta \mathrm{H}_{\text {Gues }}$. 


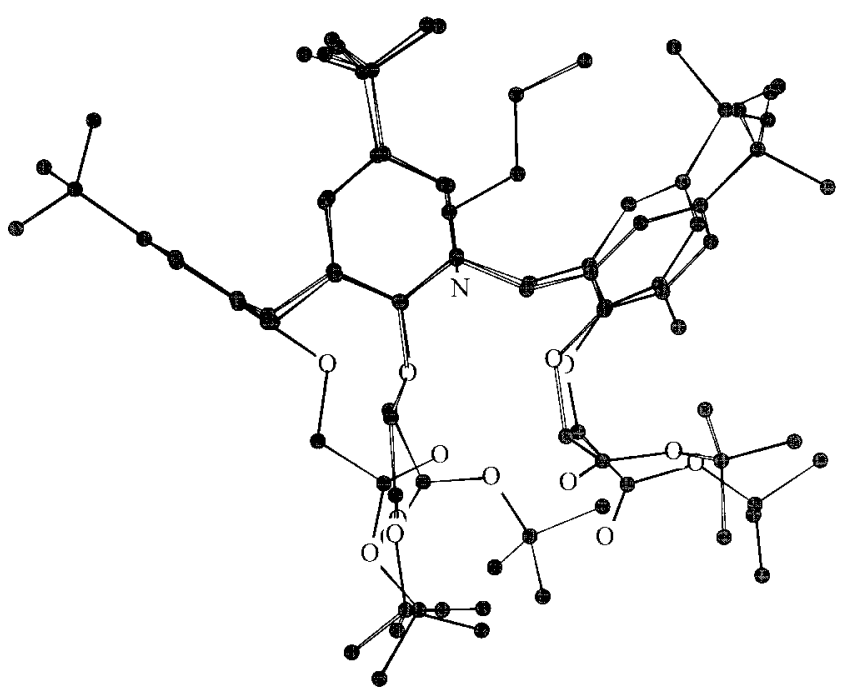

(a)

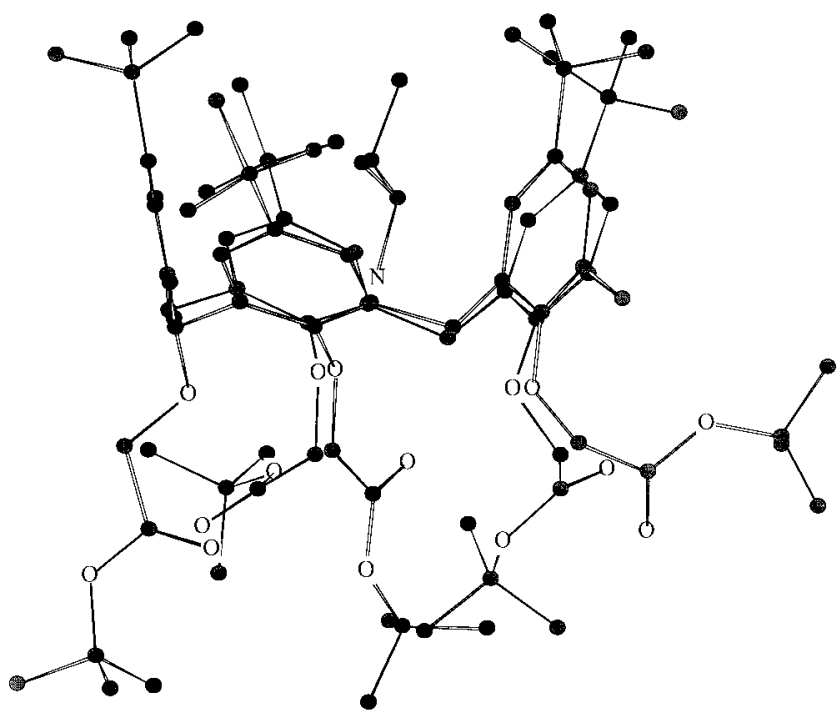

(c)

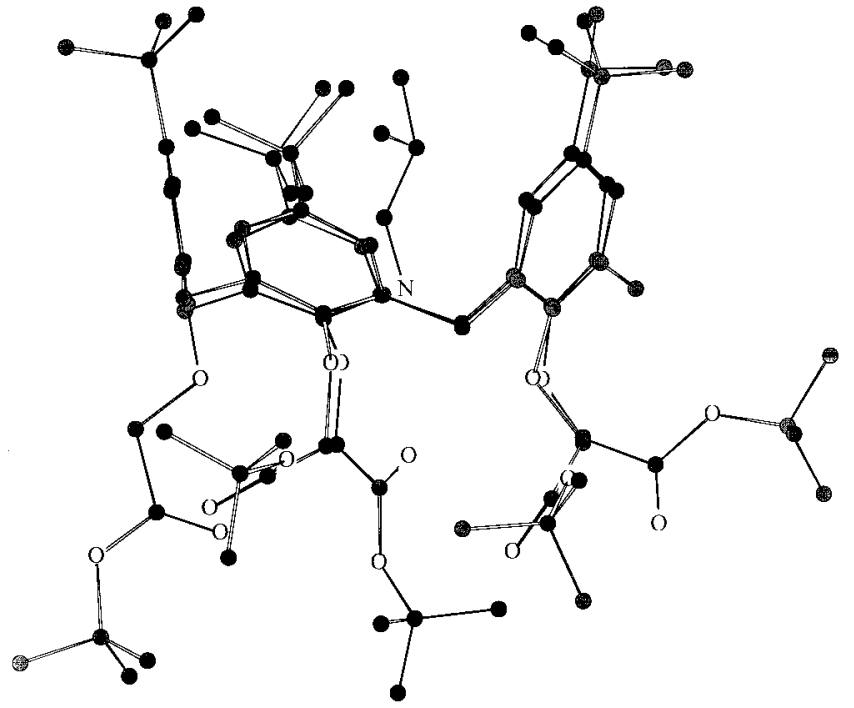

(b)

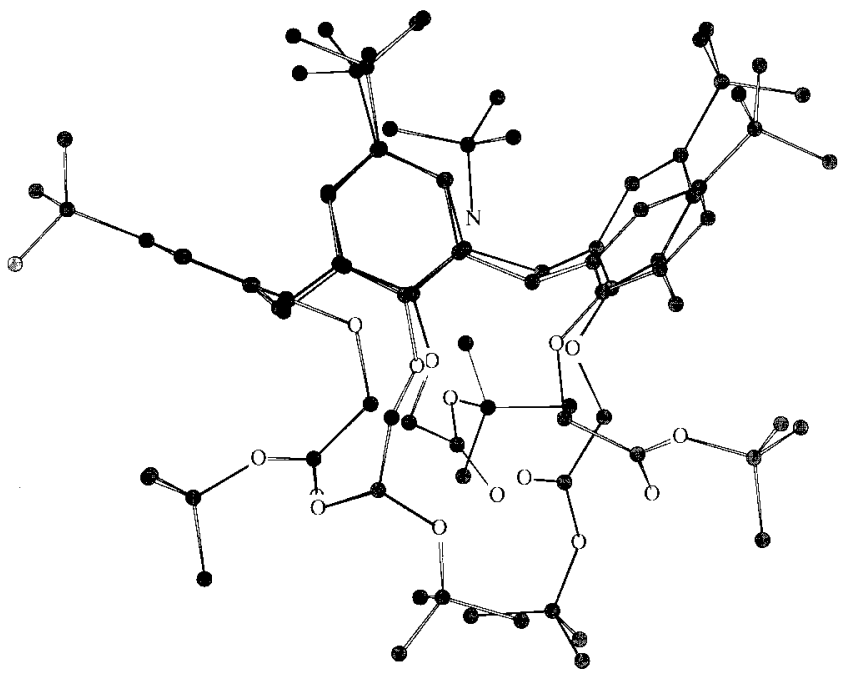

(d)

Figure 3. Calculated endo-cone confomations of 1 e complexed with (a) $n$-butyl, (b) iso-butyl, (c) sec-buty l, and (d) ten-butyl anmonium ions.

(complexation-induced shifts. CIS. up to $\Delta \delta=4$.1) for the resonances of the cavity-included alkyl chain of the guest (See Figure 3(a)). Therefore, we have focused our efforts to endo-cone-shaped complexes of host $1 \mathrm{e}$ with various butylammonium ions.

Semi-empirical Quantum Mechanical (AM1) Method. The conformations of the host and complexes obtained from MM calculations were fully re-optinized to estimate the binding energy and the formation enthalpy of the complexes using AMl seni-enipirical quantum mechanics method. Table I summarizes the relative complexation efficiency of the host 1e with four kinds of butyl ammonium isoner. The same calculation results are also presented by the enthalpies of formation in Table 2 .

In Tables 1 and 2, the more neaningful data than indivi- dual energies are the complexation energies $\left(E_{\text {complex }}-E_{H c s i}\right.$ - $\left.E_{\text {Guest }}\right)$ to cancel out the individual guest effects for the different butyl ammonium cations. As one sees from Tables 1 and 2 . the complexation energies and the complexation enthalpies for a given guest ion are exactly same. The enthalpy of formation $(\Delta \mathrm{H})$ in Table 2 is directly connected with the binding energy in Table 1 calculated from semiempirical quantum mechanics. When one compares the results of complexation energies in Table 1, t-butyl p-tentbutylcalix[5]aryl ester 1e shows the binding selectivity in following order which is in parallel with the experimental observations: $n-\mathrm{BuNH}_{2}{ }^{-}>i s o-\mathrm{BuNH}_{2}{ }^{+}>\sec -\mathrm{BuNH}_{2}{ }^{+}>$ tert-BuNH${ }_{2}^{+}$. Figure 3 shows the calculated structures of endo-cone-type complex of 1e with butylammonium cations in which hydrogen atoms are omitted for clarity. 
Table 3. MM Energies $(\mathrm{kcal} / \mathrm{mol})^{\sigma}$ of Host, Butylammonium Cations, and Complexes

\begin{tabular}{|c|c|c|c|c|}
\hline \multirow{3}{*}{$\begin{array}{l}\text { MM Energies } \\
\text { (CVEF forcefield) }\end{array}$} & \multicolumn{4}{|c|}{ Butylammonimm guest ${ }^{b}$} \\
\hline & ${ }_{n-\mathrm{Bu}}$ & $i s o-\mathrm{Bu}$ & sec-Bu & tert-Bu \\
\hline & 28.86 & 35.78 & -1.65 & -93.94 \\
\hline Host & \multicolumn{4}{|c|}{ Complexes of host with guest } \\
\hline-140.12 & -170.24 & -161.30 & -196.33 & -282.00 \\
\hline 1e Complexation ${ }^{b}$ & -58.98 & -56.96 & -54.56 & -47.94 \\
\hline
\end{tabular}

"Error limits in these calculations are $0.01 \mathrm{kcal}$ mol. ${ }^{\mathrm{E}}$ Complexation energy $=E_{\text {complex }}-E_{\text {Host }}-E_{\text {igupst }}$.

Table 4. Gibbs Free Energies ( $\mathrm{kcal} / \mathrm{mol})^{a}$ of Butylammonium Cations and Complexes

\begin{tabular}{ccccc}
\hline \multirow{2}{*}{$\Delta \mathrm{G}_{\text {calc }}$} & \multicolumn{4}{c}{ Butylammonium guest } \\
\cline { 2 - 6 } (CVFF forcefield) & ${ }_{n-\mathrm{Bu}}$ & iso-Bu & sec-Bu & tert-Bu \\
\cline { 2 - 6 } & 70.31 & 77.30 & 39.48 & -54.89 \\
\hline \multicolumn{4}{c}{ Host } & \multicolumn{4}{c}{ Complexes of host with guest } \\
1e $\quad 375.95$ & 384.20 & 391.90 & 358.08 & 272.81 \\
1e Complexation & -62.06 & -61.35 & -57.35 & -48.25 \\
\hline
\end{tabular}

"Error limits in these calculations are $0.60 \mathrm{kcal}$ mol. ${ }^{\mathrm{b}}$ Complexation Gibbs free energy $=\Delta G_{C \text { onflex }}-\Delta G_{\text {Hnst }}-\Delta G_{\text {Glest }}$.

Table 5. Distance between Nitrogen Atom of Butylammonium Ion and the Mean Plane of Five Ether-Oxygen Atoms of Host (1e)

\begin{tabular}{ccccc}
\hline & \multicolumn{4}{c}{ Butylammonium guest } \\
\hline & $n-\mathrm{Bul}$ & iso-Bu & sec-Bu & fert-Bu \\
\hline Distance $^{a}$ & 1.418 & 1.473 & 1.832 & 2.343 \\
\hline Complexation free energy $^{b}$ & -62.06 & -61.35 & -57.35 & -48.25 \\
\hline
\end{tabular}

"The distance is an average value of 61 molecular structures of local minima from MD calculation by InsightII Discover (See "Computational Methods" section for detail). "These values (kcal mol) are taken from Table 4.

Molecular Mechanics Calculations with CVFF Forcefield. Using the structures determined by the above mentioned AMl semi-enpirical quantum mechanics method, MD/ MM calculations by InsightI/Discover-1 were performed.

Table 3 reports the MM energies and complexation energies of host 1e with four different isomers of butyl anmonium ions. Host 1e shows the relative binding selectivity in following order which is in parallel with the experimental observations: $n-\mathrm{BuNH}_{3}^{+}>$iso- $-\mathrm{BuNH}_{3}^{+}>\sec -\mathrm{BuNH}_{3}^{-}>$tert$\mathrm{BuNH}_{3}^{+}$

Absolute Gibbs Free Energy. The free energies of the optimized conformers were calculated using the optimized structures obtained from the above MM (CVFF) routine by the absolute free energy calculation method in Discover ${ }^{-1}$ program.

Table 4 reports the Gibbs energies and complexation energies of host 1e with four different isomers of butyl ammonium ions. Host 1e shows the similar binding selectivity in following order: $n-\mathrm{BuNH}_{3}^{+}>i s o-\mathrm{BuNH}_{3}^{+}>\mathrm{sec}$ $\mathrm{BuNH}_{3}^{+}>$tert- $-\mathrm{BuNH}_{3}^{+}$.

One interesting thing to note from the calculated structures

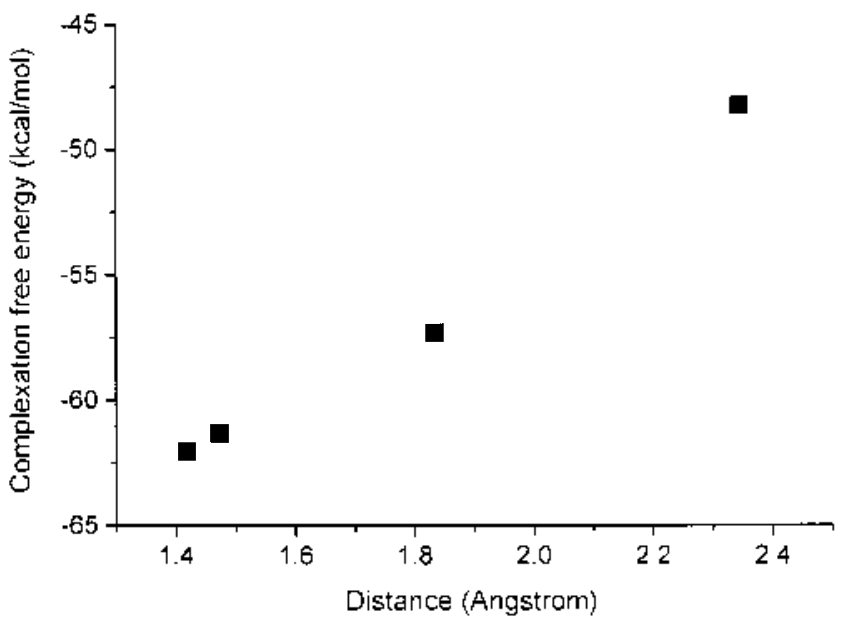

Figure 4. Plot of the calculated complexation free energies with the distances between the nitrogen atom of butylammonium ion and the mean plane of five ether-oxygen atoms of host (1e) about four different isomers of butyl ammonium guest ions.

is the relative location of the ammonium groups in the cavity of the calix[5]arene.

Table 5 shows the distance between nitrogen atom of butylammonium ion and the mean plane of five ether-oxygen atoms of host (1e) in following order: $n-\mathrm{BuNH}_{3}{ }^{+}<i s o-$ $\mathrm{BuNH}_{3}{ }^{-} \ll \sec -\mathrm{BuNH}_{3}{ }^{-} \ll$ tert-BuNH${ }_{3}{ }^{+}$.

Figure 4 shows the linear relationship of the calculated complexation free energies with the distances between the nitrogen atom of butylammonium ion and the mean plane. With increasing bulkiness of the alkyl groups of the ammonium salt. the ammonium group is located relatively away from the oxygen atoms of phenol ethers and carbonyl groups of ester, which causes $\mathrm{C}-\mathrm{H}$ bonds of butylammonium ion to be pushed out of the aromatic rings of the calix[5]arene framework. That will weaken the interactions between butyl ammonium guest and both oxygen atoms and $\pi$ electrons of host.

When one compares the calculated complexation energies of host 1e by various butyl ammonium guests in Tables 1 through 4, n-butyl ammonium guest generally has larger complexation affinity over other branched butyl ammonium ions. Trends of these calculations in vacuum agree well with the published experimental results (Table 6) for the extraction of butylammonium picrates with ester derivatives of $p$ tert-butylcalix [5]arene in solution. ${ }^{10}$

\section{Conclusion}

Using several molecular modeling programs of semi-

Table 6. Association Constants $\left(\log K_{a s s}\right)$ of Isomeric $\mathrm{BuNH}_{3}{ }^{+}$Ions (Picrate Salts) Obtained by UV Spectroscopy ${ }^{\prime \prime}$

\begin{tabular}{ccccc}
\hline $\log K_{\text {suss }}$ & \multicolumn{4}{c}{ Complexes of host with guest } \\
\hline Host & $n$ - $\mathrm{Bu}$ & iso- $\mathrm{Bu}$ & sec-Bu & tert-Bu \\
\hline $1 \mathrm{e}$ & 6.47 & 4.09 & 3.80 & 3.49 \\
\hline
\end{tabular}

Taken from reference 10. 
empirical AMl. MM and CVFF forcefields for molecular mechanics. and Finite Difference Themodynamic Integration (FDTD). we have performed conputer simulations of the complexation behaviors of the ester derivative (1e) of p-tertbutylcalix[5]arene toward a variety of butylammonium ions. For all the calculation results in these sinulations. $n$-butyl ammonium guest has nuch better complexation ability over other butyl anmonium guests. which is in good agreement with the experimental results. Although the calculations are performed under quite different condition of vacuun compared with the experimental conditions of two phase system of chloroform-water, we have successfully simulated the binding properties of calix[5] arene derivative toward model compounds of butylanmonium ions. We believe that the present sinulations provide a general and useful explanation to the molecular recognition behavior of the calix[5]arene derivatives. which will be applicable for the design of other functional ionophore systenus for the recognition of biologically important anines.

Acknowledgment. This research was supported by the Chung-Ang University research grants in 2000.

\section{References}

1. Gutsche, C. D. Calixarenes Revisited. The Royal Societ of Chemistry: Cambridge. 1998.

2. Balzani. V: De Cola L. Stpramolecular Chemistrn: Kluwer Academic Publishers: Dordrecht. The Netherlands. 1992.

3. Holecular Recognition: Chemical and Biochentical Problems: Roberts. S. M. Ed.: The Proceedings of an Intemational Symposium, Roval Society of Chemistry, Dorset Press: Dorset. Great Britain. 1989.

4. Fages. F.: Desvergne. J.-P: Kampke. K.: Bonas-Laurent. H.: Lehn. J.-M.: Meyer. M.: Albrecht-Gary. A.-M. J. Am. Chem. Soc. 1993. 115.3658

5. (a) Chang, S.-K.: Hwang. H.-S.: Son. H.: Youk. I.: Kanne. Y. S. J. Chem. Soc. Chem. Commun 1991, 217. (b) Chang, S.-K, Jang. M.: Han, S. Y.: Lee, I. H: Kang, M. H.: No, K. T. Chem. Lett. 1992. 1937. (c) Han. S. Y.: Kang. M.-H.: Jung. Y. E.: Chang. S.-K. J. Chent. Soc. Perkin Trans. 2 1994. 835

6. (a) Kubo. Y: Maeda. S.: Tokita. S.: Kubo. M. Natue 1996, 382. 522. (b) Odashima, K: Yagi. K.: Tohda, K: Umezawa, Y. Anal. Chem. 1993, 65. 1074. (c) Amecke. R.: Böhmer. V: Cacciapaglia.
R.; Cort, A. D.; Mandolini, L. Tetrahedron 1997, 53,4901.

7. Sussmant. J. L.: Harsei. M.: Frolow. F.: Oefner. C.: Goldman. A.: Toker. L.: Silman. I. Science 1991. 253.872.

8. (a) Diederich. F. Cwophomes: Stoddart. J. F.. Ed.: The Royal Society of Chemistr: Cambridge. 1991. (b) Kearney, P. C.: Misoue. L. S.; Kumpf, R. A.: Forman. J. F.: McCurdy. A.: Dougherty, D. A. J. Am. Chem. Soc. 1993. 115,9907.

9. Pappalardo. S.: Parisi. M. F. J. Ong Chem 1996. 61.8724.

10. Arnaud-Neu. F.: Fuangswasdi. S.: Notti. A.: Pappalardo. S.: Parisi. M. Angew: Chent Int Ed 1998.37. 112.

11. (a) Lee. J. Y.: Lee. S. J.: Choi. H. S.; Cho, S. J.; Kim, K. S.: Ha. T K. Chem. Phys. Lett 1995. 232,67. (b) Kim. K. S.: Lee, J. Y: Lee. S. J.: Ha, T. K.: Kim, D. H. J. Am. Chem. Soc. 1994. 116. 7399.

12. (a) Choi. H. S.: Cho. S. J.: Kim. K. S. Proc Natl Acad Sci 1998 95. 12094 (b) Kim. K. S.: Cui. C.: Cho. S. J. J. Phws. Chent 1998, 102. 461 . (c) Cho. S. J.: Hwang. H.: Park. T.: On. K.S.: Kim. K. S. J. Am. Chem. Soc. 1996. 118,485.

13. Kim. K. S.; Lee, J. Y.: Tarakeshwar. P. Chem. Rev 2000, 100. 4145.

14. Oh. K. S.: Lee. C.-W.: Choi. H. S.: Lee. S. T.: Kim. K. S. Org. Lett. 2000. 2. 2679

15. Choe. J.-I.: Kiml. K.: Chang. S.-K. Bull. Korean Chem. Soc. 2000. 21. 200.

16. Choe, J.-I.; Kim, K.; Chang. S.-K. Bull. Korean Chem. Soc. 2000. 21.465 .

17. Choe. J-I.: Chang. S.-K.: Ham. S. W.: Nanbu. S.: Aoyagi. M. Bull. Korem Chem. Soc. 2001. 22. 1248.

18. Stewart. D. R.: Krawiec. M.: Kashyap. R. P.: Watson. W. H. Gutsche. C. D. J. Am. Chem. Soc. 1995. 117, 586.

19. HyperChem Release 4. 5 ; Hypercube. Inc: Waterloo, Ontario, Canada 1995

20. (a) Burkert. U.: Allinger. N. L. Holecular Mechanics. ACS Monograph 177. American Chemical Society: Washington. D.C.. 1982. (b) MAS: Holectlar Mechantes 3: Allinger. N. L.: Yulh. Y. H. Lii, J.-H. J. Am. Chem. Soc. $1989,111,8551$

21. Discover Lsers Guide: Biosym Technologies (presently merged to MSI): San Diego. 1993.

22. (a) Singh. U. C.: Browt1. F. K.: Bash. P. A.: Kollman. P. A. J. Ain Chent. Soc. 1987. 109. 1607. (b) McCammon1. T. A. Science 1987. 238. 486. (c) Kollman. P. In Molectlor Recognition: Chemical and Biochemical Problems: Roberts, S. M., Ed.: Royal Society of Chemistry: Great Britain. 1989. (d) Lybrand, T. P. "Computer Simulation of Biomolecular Systems Using Molecular Dynamics and Free Energy Perturbation Methods" in Reviews in Computational Chemistry. Liphowitz K. B.: Boyd. D. B.. Eds.: VCH Publishers: New York. 1990. (e) Bayly. C. I: Kollman. P. A J. Am. Chem Soc. 1994, 116, 697. (f) Hwang, S. Jang. Y. H.: Ryu. G. H.; Chung. D. S. Bull. Korean Chem. Soc. 1999, 20. 1129. 